\title{
Experiência discente com o cuidado a paciente portador de Epidermodisplasia Verruciforme
}

\author{
Student experience in providing care to a patient with Epidermodysplasia Verruciformis \\ Experiencia de estudiantes con el cuidado a paciente con Epidermodisplasia Verruciforme
}

\section{Bruna Maria Cinel Correa', Ana Paula Munhoz Bolgue', Ana Paola Piloto de Oliveira", Jairo Aparecido Ayres', Bianca Sakamoto Ribeiro Paiva'I"}

' Universidade Estadual Paulista Júlio de Mesquita Filho, Faculdade de Medicina de Botucatu, Departamento de Enfermagem, Curso de Graduação em Enfermagem. Botucatu-SP, Brasil.

"Universidade Estadual Paulista Júlio de Mesquita Filho, Faculdade de Medicina de Botucatu, Hospital das Clínicas, Setor de Dermatologia. Botucatu-SP, Brasil.

"' Fundação Pio XII, Instituto de Ensino e Pesquisa, Hospital de Câncer de Barretos, Pós-Graduação em Oncologia. Barretos-SP, Brasil.

\author{
Submissão: 15-07-2011 Aprovação: 28-05-2013
}

\section{RESUMO}

Relato de experiência de situação vivenciada, em 2009, por acadêmicas de enfermagem, durante estágio da disciplina Enfermagem em Doenças Transmissíveis, na enfermaria de dermatologia de um hospital de ensino do interior paulista, em que cuidaram de um paciente com Epidermodisplasia Verruciforme. Esta é uma genodermatose rara, com susceptibilidade à infecção por diferentes tipos de papiloma vírus humanos, ocasionando alterações físicas exacerbadas e impactando o psiquismo da pessoa acometida. A assistência foi baseada na complexidade assistencial indicada pela aplicação do Sistema de Classificação de Pacientes proposto por Perroca. A experiência proporcionou aprendizado no cuidado a paciente portador de doença rara, complexa e de difícil resolução, possibilitando a necessidade de assisti-lo integralmente, percebendo-o além das lesões. Conclui-se que este tipo de experiência muito contribuiu para o crescimento das acadêmicas como futuras profissionais de enfermagem.

Descritores: Enfermagem; Epidermodisplasia Verruciforme; Cuidados de Enfermagem.

\begin{abstract}
Report of an experience of nursing students in providing care to a patient with epidermodysplasia verruciformis, during the internship in the discipline Nursing in Transmittable Diseases, at the dermatology ward of a teaching hospital, located in the state of São Paulo, Brazil, in 2009. This is a rare genodermatosis, susceptible to infection with different types of human papilloma viruses, that cause exacerbated physical changes that impact the psyche of the affected individual. Care delivery was based on the assistance complexity indicated by the application of the Patient Classification System proposed by Perroca. The experience allowed students to learn how to cope with a patient affected by a rare and complex disease, of difficult resolution, and to provide integral care to this individual, perceiving him beyond the lesions. One conclude that the experience has greatly contributed to the growth of the students as future professionals.
\end{abstract}

Key words: Nursing; Epidermodysplasia Verruciformis; Nursing Care.

\section{RESUMEN}

Relato de experiencia vivida por estudiantes de enfermería, en 2009, durante la pasantía de la disciplina de Enfermería en Enfermedades Transmisibles, en la sala de dermatología de un hospital universitario del estado de São Paulo, Brasil, donde cuidarán a uno paciente con Epidermodisplasia Verruciforme. Esta es una genodermatosis rara, con susceptibilidad para la infección por diferentes tipos de virus del papiloma humano, causando cambios físicos exasperados e impacto en la psiquis de la persona afectada. La asistencia esté basada en la complejidad de la atención, segundo la aplicación del Sistema de Clasificación de Pacientes propuesto por Perroca. A experiencia proporciono aprendizaje en el cuidado del paciente con una enfermedad rara, compleja y de difícil cura, dando la posibilidad a las estudiantes de asistirlo integralmente, más allá de las lesiones. Concluye-se que este tipo de experiencia contribuyó para el crecimiento de las estudiantes como futuros profesionales. Palabras clave: Enfermería; Epidermodisplasia Verruciformis; Cuidados de Enfermería.

\section{AUTOR CORRESPONDENTE Ana Paola Piloto de Oliveira E-mail: bsrpaiva@hotmail.com}




\section{INTRODUÇÃO}

A Epidermodisplasia Verruciforme (EV) é uma genodermatose $\operatorname{rara}^{(1-10)}$, de distribuição universal ${ }^{(3,8)}$. Descrita por Lewandowsky e Lutz em 1922(4,8), caracteriza-se pela susceptibilidade à infecção por diferentes tipos de papiloma vírus humanos $(\mathrm{HPV})^{(1-8,10-12)}$. Por ser patologia incomum, apresentando casos isolados no mundo, torna-se difícil mensurar com exatidão sua incidência ${ }^{(9)}$. Autores descrevem que há influência de fatores genéticos, infecciosos, ambientais e imunológicos, tratando-se de uma doença complexa ${ }^{(9)}$. Sua distribuição pode ser familiar ou isolada. Embora haja relatos de possível herança recessiva ligada ao cromossomo $\mathrm{X}$, alguns autores consideram que a transmissão ocorre pelo mecanismo autossômico recessivo ${ }^{(5-10)}$, explicado pelo fato de apresentar elevada incidência familiar, por consanguinidade, raramente acometendo gerações sucessivas ${ }^{(1-3,10)}$. Acrescenta-se ainda que a doença ocasiona alterações físicas, impactando o psiquismo da pessoa acometida, sendo extremamente necessário o suporte emocional e psicológico ${ }^{(8)}$.

Os vírus encontrados na EV são em sua maioria específicos da doença, denominados HPVs associados à EV (HPVEV). A patologia normalmente se inicia na infância, entre os cinco e onze anos de idade, manifestando-se por múltiplas lesões verrucosas planas-símile e/ou máculas semelhantes à pitiríase versicolor $^{(1-3,5-6,8-12)}$. Após determinado período, aproximadamente aos 30 anos, cerca de 30 a 50\% dos doentes podem desenvolver câncer de pele múltiplos, geralmente associado a áreas de intensa exposição solar (1-3,5,7-12).

O portador apresenta deficiências imunológicas, principalmente da imunidade mediada por células, além disso, há presença de polimorfismos genéticos no complexo maior de histocompatibilidade, o que determina inadequada apresentação de antígenos específicos do HPV às células de defesa. Assim, os doentes desenvolvem infecção disseminada e de longa duração pelo vírus, podendo desencadear distúrbios tardios inespecíficos de imunidade celular ${ }^{(1-3)}$. Acomete ambos os sexos e qualquer etnia; e cursa sem sintomas ou com discreto prurido ${ }^{(1-3)}$.

A EV é aceita como condição pré-maligna, sendo classificada em três formas: benigna, que se caracteriza por verrugas planas, associadas aos HPVs não-oncogênicos dos subtipos 3 e/ou 10; maligna, com características de polimorfismo com tendência à malignização, associada a múltiplos HPVEVs sendo alguns oncogênicos, dos subtipos 3,4,5, $7^{(11)}$; ou mista, caracterizada pela presença inicial de verrugas planas, seguida pelo aparecimento do polimorfismo característico da forma maligna ${ }^{(1-2)}$.

A transformação maligna ocorre em aproximadamente de 30 a 50\% dos casos, sendo associada a fatores como os HPVEVs oncogênicos, genéticos do hospedeiro e à ação de co-carcinógenos extrínsecos, principalmente exposição a raios ultravioleta $^{(11)}$, radioterapia ${ }^{(2)}$, tabagismo e imunossupressão ${ }^{(3,12)}$. Os tumores malignos mais frequentemente encontrados são o carcinoma in situ, o carcinoma espinocelular e o carcinoma basocelular. Essas neoplasias são localmente invasivas e têm baixo potencial metastático, exceto quando associados a outros co-carcinógenos, principalmente radioterapia local ${ }^{(9)}$.
Não há tratamento específico convencional; portanto, atualmente utilizam-se de associações terapêuticas com resultados satisfatórios, dentre as quais se destacam os retinóides orais (acitretina) e interferon ${ }^{(8,11-12)}$. Os retinóides orais exercem efeitos benéficos devido à ação antiviral e antiproliferativa no controle da diferenciação das células epiteliais ${ }^{(11)}$. O interferon alfa-2a sistêmico ou intralesional, em doses que variam entre 1 a 9 milhões de unidades/dia, induz o desaparecimento das alterações histopatológicas encontradas na EV pela ação imunomoduladora, antiviral e antiproliferativa. No entanto, esta terapêutica pode produzir reações adversas como febre baixa (78\%), astenia (78\%) e mialgias (65\%), que desaparecem 12 horas após o uso da medicação(3).

Estudos mostram que a associação da acitretina oral $0,75 \mathrm{mg} / \mathrm{kg} /$ dia e interferon (IFN) alfa-2a 3.000.000UI via subcutânea, três vezes por semana, possui efeito satisfatório após 30 dias, com desaparecimento de mais de 50\% das lesões, principalmente no tronco, e diminuição da espessura das remanescentes em cerca de $40 \%{ }^{(3)}$. Óbitos relacionados à doença são raros. Quando ocorrem são relativos à invasão de estruturas locais ou às metástases das neoplasias ${ }^{(9)}$.

\section{RELATO DA EXPERIÊNCIA}

No decorrer do estágio da disciplina de Enfermagem em Doenças Transmissíveis, realizado na Enfermaria de Dermatologia de um hospital de ensino do interior paulista, cuidou-se de paciente portador de Epidermodisplasia Verruciforme, sexo masculino, 55 anos, casado, aposentado, procedente do Estado de Minas Gerais, admitido na instituição em consequência de lesões vegetantes e verrucosas nas mãos, pernas e pés, ulcerações interdigitais e duas úlceras de aproximadamente $10 \mathrm{~cm}$ de diâmetro, próximas à região do maléolo, de fundo colonizado, com secreção esverdeada, odor fétido e ausência de sinais inflamatórios (Figura 1). A internação causou agitação e comentários entre profissionais e demais pacientes ao primeiro contato, pois se trata de doença rara e conhecida popularmente como "Homem árvore".

Segundo relatos do paciente, com 12 anos de idade observou aparecimento de verrugas em algumas regiões das mãos, com surgimento de outras nos pés e pernas, percebendo que houve crescimento progressivo. Fez tratamento homeopático na cidade de origem sem melhora, relatou ainda, nunca ter feito tratamento específico. Porém, em 2000 foi tratado de câncer de pele, provavelmente associado à patologia de base, mas apresentou melhora das lesões. Além disso, é portador de Albinismo Óculocutâneo, com acuidades visual e auditiva diminuídas; nega outras patologias, consanguinidade e casos semelhantes na família.

No período de internação foram realizados exames de rotina sem apresentar alterações, apenas o teste tuberculínico (PPD) foi considerado como reator forte, indicando a tuberculose infecção. O esquema terapêutico estabelecido incluía analgésicos, antifúngicos sistêmicos e tópicos, anticoagulante, antipsoriático e agente tópico com ação desbridante.

Durante as interações percebeu-se que era um paciente comunicativo, tranquilo quanto à sua autoimagem, e que realizava 
Figura 1 - Paciente portador de EV. Lesões de membros superiores e inferiores.

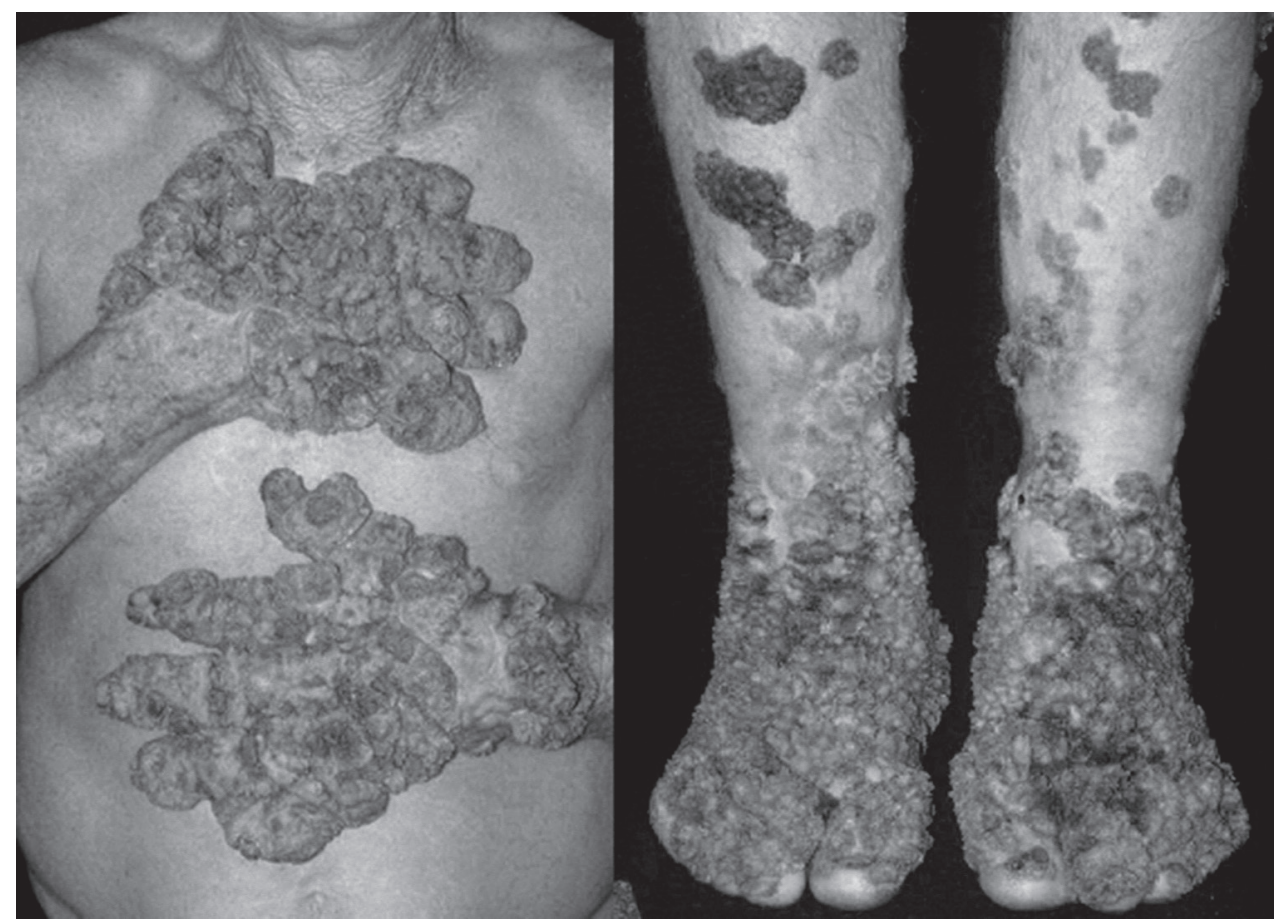

pela força que exercia no ato; percebeu-se com esta atitude que sentia necessidade do tocar e, portanto, procurou-se intensificar este contato sem receio e com carinho.

Esta experiência possibilitou verificar a necessidade de assistir o paciente em todos os aspectos, percebendo-o além das lesões. Acrescenta-se ainda, que o mesmo era extremamente receptivo, alegre, foi questionado se havia se submetido a algum tratamento para "tristeza", referiu que não e acrescentou que não teria motivo para ser triste, nos dando um exemplo de vida.

Após a realização das interações e cuidados, foi possível estabelecer alguns diagnósticos de enfermagem que facilitaram o maior conhecimento do paciente e a pro-

o autocuidado sem auxílio. Ao exame físico, não apresentou alterações; porém, eram evidentes as numerosas lesões verrucosas irregulares, no dorso das mãos e pés, e isoladas nas pernas, com odor fétido. Como conduta de enfermagem iniciou-se com higienização das lesões com água e sabão antisséptico e secagem criteriosa para evitar colonização de microorganismos. As úlceras maleolares, com bordas regulares, superficiais, apresentavam tecido de granulação e fibrinoso, foi aplicado sulfadiazina de prata nos dois primeiros dias e, posteriormente, tratamento tópico com papaína a 6\%, com redução do tecido fibrinótico e aumento da área de granulação.

Aceitava bem a terapêutica proposta e contribuía na execução dos cuidados, realizando seu autocuidado e se movimentando sem auxílio, o que facilitava sua exposição ao sol com o objetivo de diminuir a umidade das lesões.

O primeiro contato foi impactante, tanto pelo odor quanto pela imagem. Nem se conseguia imaginar como iniciar os cuidados. Porém, percebemos que o paciente era extremamente acessível, o que facilitou as interações e intervenções de enfermagem. Ao observar a execução da higienização e do curativo realizado pela supervisora, surgiram questões do tipo "seríamos capazes de executar tal procedimento com naturalidade?" Ao término do período concluímos que seríamos capazes de enfrentar a situação, procedendo com os cuidados com mais segurança.

No dia seguinte, após nos reapresentamos, nos paramentamos com material de proteção por contato e iniciamos o cuidado ainda com insegurança. No entanto, o diálogo foi estabelecido com a oportunidade de conhecermos mais sobre $\mathrm{O}$ paciente. Houve reciprocidade empática, o que facilitou a execução dos procedimentos com maior segurança. Ao secarmos as mãos do paciente, observou-se que buscava maior contato, blemática que o envolvia neste período: Risco de infecção, caracterizado por defesas primárias inadequadas, destruição de tecidos e imunossupressão; Integridade da pele prejudicada, caracterizada por rompimento da superfície da pele, evidenciado por lesões verrucosas, aumento da umidade e albinismo; Distúrbio na imagem corporal, caracterizado por mudança real na estrutura, evidenciado pela doença e pelas lesões.

Em relação ao último diagnóstico a alteração da imagem corporal era evidente pelas inúmeras lesões que causavam certa deformidade. Porém, o paciente não demonstrava comportamentos negativos ou rejeição da imagem corporal, e tinha, durante o período de internação, comportamento social normal.

\section{ASSISTÊNCIA DE ENFERMAGEM}

Utilizamos um instrumento de classificação de pacientes, através do sistema de avaliação de indicadores críticos, construído e validado por Perroca ${ }^{(13)}$, baseado nas necessidades individuais de cuidado de enfermagem.

O instrumento utiliza treze indicadores críticos que abrangem a dimensão biológica e psicossocial do cuidado. Cada um desses indicadores aponta a intensidade crescente de complexidade assistencial. A terminologia indicadores críticos foi adotada para indicar as necessidades de cuidado de enfermagem no paciente, que, quando associadas entre si, identificam a categoria de cuidado a que ele pertence ${ }^{(13)}$. Por meio de sua aplicação podemos classificar o paciente em quatro categorias de cuidados, mínimos, intermediários, semi-intensivos e intensivos. O escore mínimo a ser obtido é de 13 e o máximo de 65 pontos $^{(14)}$. 
Com a aplicação do instrumento o paciente em questão foi classificado na categoria de cuidados mínimos, o que corresponde aos estáveis clinicamente e capazes de realizar o autocuidado.

\section{CONCLUSÃO}

Esta experiência proporcionou aprendizado na assistência ao paciente portador de doença rara, complexa e de difícil resolução. Sentiu-se a necessidade de classificar os cuidados por complexidade, método que facilitou as condutas de enfermagem, tornando-o independente da equipe, promovendo a autonomia, uma vez que os cuidados terão continuidade em seu domicílio. Percebeu-se ainda que, apesar do comprometimento físico e alteração da autoimagem, o paciente se comportava dentro da normalidade e transmitia tranquilidade. Notadamente apresentava-se receptivo, sociável e emocionalmente equilibrado, desencadeando uma transformação em nossa atitude profissional, passando as lesões serem insignificantes em relação às interações. Conclui-se que este tipo de experiência contribuiu muito para o crescimento enquanto futuros profissionais, principalmente no que se refere à importância da promoção do cuidado de maneira integral.

\section{REFERÊNCIAS}

1. Jorde LB, Carey JC, Bamshad MJ, White RL. Genética Médica. 2. ed. Rio de Janeiro: Guanabara Koogan; 2000. p. 60.

2. Oliveira WRP, Festa Neto C, Tyring SK. Aspectos Clínicos da Epidermodisplasia Verruciforme. An Bras Dermatol 2002;77(5):545-56.

3. Silva CS, Pires MC, Ramos RO, Sittart JAS. Epidermodisplasia verruciforme: tratamento combinado com acitretina e interferon alfa-2a. An Bras Dermatol 2006;81(6):595-7.

4. Machado Filho CD, Almeida FA, Vieira CG, Juazeiro PP, Araújo AC. Epidermodisplasia verruciforme - Estudo imunológico de três casos. An Bras Dermatol 1984;59(1):23-6.

5. Robati RM, Marefat A, Saeedi M, Rahmati-Roodsari M, Asadi-Kani Z. Four familial cases of epidermodysplasia verruciformis: mother and three sons. Dermatol Online J 2009;15(4):8

6. Rogers HD, Macgregor JL, Nord KM, Tyring S, Rady P, Engler DE, Grossman ME. Acquired epidermodysplasia verruciformis. J Am Acad Dermatol 2009;60(2):315-20.

7. Orth G. Host defenses against human papillomaviruses: lessons from epidermodysplasia verruciformis. Curr Top Microbiol Immunol 2008;321:59-83.

8. Meissner MCG, Gon AS, Bedrossian AAD, Sonnberger
JCN, Reis CRC. Epidermodisplasia verruciforme: relato de caso. An Bras Dermatol 2005;80(Suppl 2):S77-188.

9. Barcelos ACN. Análise comparativa da expressão de citoqueratinas, involucrina, filagrina e e-caderina em verrugas planas e em lesões do tipo verruga plana na Epidermodisplasia Verruciforme. São Paulo. Dissertação [Mestrado em Ciências] - Faculdade de Medicina da USP; 2008.

10. Harris AJ, Purdie K, Leigh IM, Proby C, Burge S. A novel human papillomavirus identified in epidermodysplasia verruciformis. Br J Dermatol 1997;136(4):587-91.

11. Ansarin $H$, Tajziehchi $L$, Shaianfar N. A case of epidermodysplasia verruciformis with squamous cell carcinomas on non-sun-exposed areas of skin. Arch Iran Med 2007;10(2):261-3.

12. Berk DR, Bruckner AL, Lu D. Epidermodysplasia verruciform-like lesions in an HIV patient. Dermatol Online J 2009; 15(1):1.

13. Perroca MG. Instrumento de classificação de pacientes de Perroca: validação clínica. São Paulo. Tese [Doutorado em Enfermagem] - Escola de Enfermagem da USP; 2000.

14. Araújo VB, Perroca MG, Jericó MC. Variabilidade da complexidade assistencial do paciente em relação à equipe de enfermagem. Rev latino-Am Enferm 2009;17(1):34-9. 